\title{
Relationships between sleep patterns and metabolic profile in patients maintained on antipsychotics: a cross-sectional comparative study
}

This article was published in the following Dove Press journal:

Neuropsychiatric Disease and Treatment

\author{
Nancy Kiwan' \\ Ziyad Mahfoud ${ }^{2,3}$ \\ Suhaila Ghuloum ${ }^{4}$ \\ Arij Yehya' \\ Samer Hammoudeh ${ }^{\prime}$ \\ Yahya Hani ${ }^{4}$ \\ Rifka Chamali' \\ Iman Amro' \\ Dennis Mook-Kanamori ${ }^{5}$ \\ Hassen Al-Amin ${ }^{6}$ \\ 'Department of Research, Weill Cornell \\ Medicine - Qatar, Doha, Qatar; \\ ${ }^{2}$ Department of Health Policy and \\ Research, Weill Cornell Medicine - Qatar, \\ Doha, Qatar; ${ }^{3}$ Department of Healthcare \\ Policy and Research, Weill Cornell \\ Medicine, New York, NY, USA; \\ ${ }^{4}$ Psychiatry Hospital, Hamad Medical \\ Corporation, Doha, Qatar; ${ }^{5}$ Department \\ of Physiology and Biophysics, Weill \\ Cornell Medicine - Qatar, Doha, Qatar; \\ ${ }^{6}$ Department of Psychiatry, Weill Cornell \\ Medicine - Qatar, Doha, Qatar
}

Correspondence: Hassen Al-Amin Department of Psychiatry, Weill Cornell Medicine - Qatar, Education City, P.O.

Box 24I44, Doha, Qatar

Tel +97444928318

Fax +97444928377

Email haa2019@qatar-med.cornell.edu
Background: Disturbances in sleep duration and quality have been associated with obesity and other metabolic changes. Patients with mental disorders (MD) are known to have more sleep problems, and antipsychotics (AP), used in the treatment of these patients, can also cause weight gain. This study aimed to compare the self-reported sleep patterns between psychiatric patients (on or off AP) and controls. We also evaluated the associations between the clinical and metabolic profiles with short or long sleep duration.

Methods: A total of 339 subjects was recruited: Mentally ill patients maintained on AP for at least six months $(\mathrm{MD}+\mathrm{AP}, \mathrm{n}=112)$, patients not taking AP for at least the last six months before enrollment (MD/noAP, $\mathrm{n}=101)$, and non-psychiatry controls $(\mathrm{HC}, \mathrm{n}=126)$. Multinomial regression analysis was applied to find the predictors of irregular sleep duration in this sample.

Results: More mentally ill patients (MD+AP and MD/noAP) reported a sleep duration of $>8 \mathrm{hrs}$ than HC. Patients from MD/noAP showed more insomnia than HC. Sleep disturbances were significantly more frequent in MD+AP than HC. Participants who reported sleeping $>8 \mathrm{hrs}$ had higher body mass index and waist circumference than those who slept $<7 \mathrm{hrs}$.

Conclusion: Female gender, central obesity and being mentally ill were independently associated with long sleep duration $(>8 \mathrm{~h})$ in the population of Qatar.

Keywords: sleep duration, sleep quality, metabolic syndrome, mental disorders, antipsychotics

\section{Introduction}

Patients with mental disorders (MD) have increased rates of diabetes mellitus (DM) and cardiovascular diseases, ${ }^{1}$ resulting in higher mortality rates. ${ }^{2}$ These increased rates are related to the mental disorder itself, the effects of antipsychotics (AP) used in treatment, lifestyle behaviors, such as physical inactivity, and suboptimal sleep quality (SQY) and duration $(\mathrm{SDN}) .^{3}$ Disturbed sleep was found in $30-80 \%$ of schizophrenia patients, manifesting as increased sleep latency and reduced sleep efficiency and total sleep time. ${ }^{4}$ Sleep difficulties are also frequently reported in psychiatric disorders like schizophrenia, depression, bipolar disorder and anxiety, where the sleep cycle of these patients is altered. ${ }^{5}$ Many patients with MD might also receive first generation (FGA) or second generation (SGA) AP which alter the sleep-wake cycle. FGAs significantly decrease sleep latency and increase sleep efficiency, while SGAs significantly increase total sleep time. ${ }^{6}$ As such, AP might improve sleep problems in mentally ill patients, but the increase in SDN can reach unhealthy limits that can affect patient functioning and productivity. ${ }^{7}$ 
Sufficient SDN and SQY are essential for the regular functioning of hormonal and metabolic activities on a daily basis. Irregular SDN is known to be correlated with DM, obesity and cardiovascular diseases. ${ }^{8}$ Studies have also revealed that poor SQY, even when not accompanied by changes in SDN, is associated with an increase in body fat, body mass index (BMI), waist circumference, blood glucose, and insulin resistance. ${ }^{9}$ Some of these risk factors cluster together, resulting in the development of metabolic syndrome (MetS), which is known to increase the risk of cardiovascular disease and all-cause mortality. ${ }^{10}$ Recent studies have demonstrated a U-shaped association between SDN and MetS, where participants with both short and long SDN had a higher prevalence of MetS than participants with normal SDN (usually 7-8 h). ${ }^{11}$ However, other studies reported that only either short or long SDN was associated with MetS, ${ }^{12}$ and others established that only some components of MetS were related to short SDN (central obesity and hypertension), while other elements were associated with extended SDN (hyperglycemia and high triglyceride level). ${ }^{13}$ Thus, more studies are needed to further the understanding of the relationships between the sleep profile and various metabolic changes.

Moreover, despite the frequent sleep disturbances in patients with mental illness and the impact of AP on sleep and metabolic profiles, there are no studies that assessed these related components (MD, antipsychotic use, sleep problems, and metabolic changes) together. The primary objective of this project was to compare the sleep patterns among three groups: mentally ill patients maintained on AP for at least six months (MD+AP), another group of patients not taking AP for at least the last six months before enrollment (MD/noAP), and healthy controls (HC). We hypothesized that the group on AP would have the longest SDN and worst SQY. Our secondary objective was to study if the metabolic abnormalities are associated with long or short SDN after controlling for the other demographic and clinical factors. Our hypothesis was that obesity and intake of AP are associated with longer SDN.

\section{Methods}

\section{Participants}

The subjects were recruited to study the prevalence and incidence of MetS in patients receiving AP. The sample size was determined based on that objective and aimed for a $20 \%$ difference regarding MetS, a power of $90 \%$, and a significance level of 5\%. Please refer to the prevalence study for further details on methodology. ${ }^{14}$ The study was approved by the Institutional Review Boards of Weill Cornell Medicine-Qatar and Hamad Medical Corporation (HMC)-Qatar and was conducted between May 2013 and June 2015. Participants signed a written informed consent after receiving precise information about the procedures. Patients were recruited from the Department of Psychiatry in HMC. The control group was recruited from a primary health care center in Doha. Subjects were referred by their treatment teams, and approximately $40 \%$ of them agreed to participate. The research team did not interfere with the treatment plans of these subjects as they were followed up by their psychiatrists. The group that was off AP were mostly patients who were not compliant with their medications and were not taking any for at least the last six months.

The inclusion criteria for the MD+AP group were: (a) age between 18 and 65, (b) diagnosis of a mental disorder (except eating disorders), (c) being on AP for at least the last six months, and (d) absence of MetS. The exclusion criteria were: (a) receiving Lithium, Nortriptyline or Amitriptyline for the past three months (as these medications can cause weight gain) and (b) having current or past (last six months) substance abuse. The inclusion and exclusion criteria for the MD/noAP group were the same as above except that the patients should not have received any AP in the past six months. The inclusion criteria for the control group mandated the absence of a mental disorder and no intake of AP.

\section{Measures and definitions}

The psychiatric diagnosis of patients was obtained from their medical charts, which relied on the Diagnostic and Statistical Manual of Mental Disorders (DSM-IV-TR) criteria. The control subjects were screened using the Mini International Neuropsychiatric Interview (MINI, version 6) ${ }^{15}$ to rule out any psychiatric disorder. Participants also answered a set of structured questionnaires that addressed the sociodemographics, medical and psychiatric history, and sleep patterns. The diagnoses and medication types were obtained from the medical records as recorded by the treatment team of each participant. The chlorpromazine equivalent AP dose was calculated for each AP using the method by Andreasen et $\mathrm{al}^{16}$. Vital signs (heart rate and blood pressure) and anthropometric measures (height, weight and waist circumference) were obtained from all subjects. Four raters were trained to administer these questionnaires and measures identically to all participants. The MINI and questionnaires were administered in English and Arabic and were designed for the population in 
Qatar. The raters established good inter-rater reliability before administering the questionnaires to study subjects. Blood samples were taken within 1-2 days of obtaining informed consent, and subjects were asked to fast for 10-12 hrs before the blood draw. Blood tests (lipid profile, glycosylated hemoglobin, and fasting glucose) were carried out according to the standardized procedures of the laboratories of HMC. Consequently, the presence or absence of MetS was determined according to the International Diabetes Federation (IDF) worldwide criteria. ${ }^{17}$

Sleep patterns were determined by a sleep questionnaire that is detailed in the Table S1. A sleep score was devised based on this questionnaire. The score aimed to measure subjective SQY, sleep latency, SDN, sleep disturbances and daytime dysfunction. Calculation of component scores based on the questionnaire is illustrated in the Table S2. Higher scores are indicative of a poorer quality of sleep. Total SDN was calculated by adding the number of hours slept at night and during day nap, and was divided into three groups: 1) $<7 \mathrm{~h}, 2) 7-8 \mathrm{~h}$ and 3) $>8 \mathrm{~h}$. The $7-8 \mathrm{~h}$ category was defined as the reference category; short SDN was identified as $<7 \mathrm{~h}$, and long $\mathrm{SDN}$ as $>8 \mathrm{~h}$. This grouping was chosen based on population studies that assessed cardiometabolic risk and mortality in adults. ${ }^{18}$

\section{Statistical analysis}

All statistical analyses were performed using the IBMSPSS version 24 (IBM Corp, Armonk, NY, 2015), with statistical significance set at 0.05 . Continuous variables were presented as the mean \pm standard deviation (SD) or median \pm interquartile range (IQR), while frequency distributions were used for categorical variables. For the assessment of different characteristics across the subject groups, participants were divided into three groups: $\mathrm{HC}$, $\mathrm{MD}+\mathrm{AP}$, and MD/noAP. To compare variables across groups, chi-square tests were used to analyze categorical variables, and one-way analysis of variance (ANOVA) to analyze continuous variables. The Kolmogorov-Smirnov test was used to assess normality. In this regard, MannWhitney was used. Similarly, subject characteristics were compared across the SDN subgroups $(<7 \mathrm{~h}, 7-8 \mathrm{~h}$, and $>8 \mathrm{~h}$ ). All analyses were done with Bonferroni corrections for multiple comparisons. To assess the factors that are contributing to differences in SDN in our sample, multinomial logistic regression (Stepwise Model) was done using the above nominal sleep grouping as the dependent measure and the significant and clinically relevant variables from the above analyses as the independent predictors.

\section{Results \\ Sample characteristics by illness and treatment groups (Table I)}

The mean age was not significantly different in the three groups, and most of the subjects were between 25 and 44 years old. The following sociodemographic variables showed significant differences between the three groups: gender $\left(\chi^{2}=6.398, \quad p=0.041\right)$, nationality $\left(\chi^{2}=39.804\right.$, $p<0.001)$, marital status $\left(\chi^{2}=32.223, p<0.001\right)$, education $\left(\chi^{2}=33.491, p<0.001\right)$, and employment status $\left(\chi^{2}=77.124\right.$, $p<0.001)$. Bonferroni-adjusted post hoc comparisons showed that there were no gender differences between the two patient groups, but there were significantly more males in MD/noAP group compared to HC. The number of Qataris was significantly higher in $\mathrm{MD}+\mathrm{AP}$, whereas that of South Asians was higher in the $\mathrm{HC}$ and MD/noAP groups. The majority of the subjects in the two patient groups were single, unemployed and mostly with intermediate schooling, while more subjects in the HC group were married and employed with a graduate degree (Table 1).

The smoking status $\left(\chi^{2}=26.474, p<0.001\right)$, systolic blood pressure $(\mathrm{SBP})\left(\mathrm{F}_{2,336}=16.194, p<0.001\right)$, diastolic blood pressure $(\mathrm{DBP})\left(\mathrm{F}_{2,336}=14.899, p<0.001\right), \mathrm{BMI}\left(\mathrm{F}_{2,325}=15.799\right.$, $p<0.001)$, waist circumference $\left(\mathrm{F}_{2,335}=13.742, p<0.001\right)$, and weight $\left(\mathrm{F}_{2,331}=16.542, p<0.001\right)$ were significantly different between the three subject groups. Post hoc comparisons (Table 1) showed that the two patient groups had more smokers and higher blood pressure than HC. The patients on AP had higher weight and waist circumference compared to the other two groups, but BMI was significantly the lowest in patients not taking AP, even when compared to the control group (Table 1). The other variables (history of hypertension, cardiac disease, DM, fasting blood glucose, and cholesterol and triglyceride levels) were not significantly different between the three groups. The presence of MetS as per IDF criteria was the highest in MD+AP (35.7\%) and the lowest in $\mathrm{MD} /$ noAP (21.8\%). However, these differences did not reach statistical significance $\left(\chi^{2}=5.027, p=0.081\right)$.

\section{Psychiatric and medication profiles of the participants (Table 2)}

The group MD/AP included more patients with bipolar disorder compared to MD/noAP. All the patients in MD/ 
Table I Sample characteristics by illness and treatment groups

\begin{tabular}{|c|c|c|c|}
\hline & HC $(n=126)$ & $M D+A P(n=|| 2)$ & MD/noAP $(n=|0|)$ \\
\hline Age (mean $\pm S D)$ & $35.05 \pm 8.17$ & $35.73 \pm 10.28$ & $34.16 \pm 8.93$ \\
\hline \multicolumn{4}{|l|}{ Gender n (\%) } \\
\hline Male & $72(57.1 \%)$ & $73(65.2 \%)$ & $74(73.3 \%)^{*}$ \\
\hline Female & $54(42.9 \%) \ddagger$ & 39 (34.8\%) & $27(26.7 \%)$ \\
\hline \multicolumn{4}{|l|}{ Nationality n (\%) } \\
\hline Qatari & $22(17.5 \%)$ & $52(46.4 \%)^{*} \ddagger$ & $20(19.8 \%)$ \\
\hline Arab (non-Qatari) & $35(27.8 \%)$ & $27(24.1 \%)$ & $19(18.8 \%)$ \\
\hline South Asian & $57(45.2 \%)+$ & $24(21.4 \%)$ & $43(42.6 \%)+$ \\
\hline Other & $12(9.5 \%)$ & $9(8.0 \%)$ & $19(18.8 \%)$ \\
\hline \multicolumn{4}{|l|}{ Marital status n (\%) } \\
\hline Single & $35(27.8 \%)$ & $57(50.9 \%)^{*}$ & $44(43.6 \%)^{*}$ \\
\hline Married & $90(71.4 \%)^{\dagger} \ddagger$ & $43(38.4 \%)$ & $53(52.5 \%)$ \\
\hline Divorced/Widowed & I (0.8\%) & $12(10.7 \%)^{*}$ & $4(4.0 \%)$ \\
\hline \multicolumn{4}{|l|}{ Education n (\%) } \\
\hline None & $4(3.2 \%)$ & $4(3.6 \%)$ & $8(8.0 \%)$ \\
\hline Elementary/Intermediate & $20(16.0 \%)$ & $35(31.5 \%)^{*}$ & $37(37.0 \%)^{*}$ \\
\hline Secondary & $29(23.2 \%)$ & 37 (33.3\%) & $25(25.0 \%)$ \\
\hline Vocational/College/Graduate & $72(57.6 \%)^{\dagger} \ddagger$ & $35(31.5 \%)$ & $30(30.0 \%)$ \\
\hline \multicolumn{4}{|l|}{ Employment n (\%) } \\
\hline Employed & $116(94.3 \%)^{\dagger} \ddagger$ & 47 (42.0\%) & $73(72.3 \%)^{\dagger}$ \\
\hline Unemployed & $7(5.7 \%)$ & $65(58.0 \%) * \ddagger$ & $28(27.7 \%)^{*}$ \\
\hline Smoker n (\%) Yes & $27(21.4 \%)$ & $58(51.8 \%)^{*}$ & $47(46.5 \%)^{*}$ \\
\hline BMI $\left(\mathrm{kg} / \mathrm{m}^{2}\right)($ mean $\pm \mathrm{SD})$ & $27.66 \pm 5.24 \ddagger$ & $29.12 \pm 6.95 \ddagger$ & $24.56 \pm 5.29$ \\
\hline $\mathrm{SBP}(\mathrm{mm} \mathrm{Hg})($ mean $\pm \mathrm{SD})$ & $120.19 \pm 15.46$ & $127.92 \pm 13.56 *$ & $|30.25 \pm| 2.9 \mid *$ \\
\hline $\mathrm{DBP}(\mathrm{mm} \mathrm{Hg})($ mean $\pm \mathrm{SD})$ & $74.77 \pm 12.34$ & $81.44 \pm 10.70 *$ & $82.25 \pm 11.35 *$ \\
\hline $\mathrm{FBG}(\mathrm{mmol} / \mathrm{L})($ mean $\pm \mathrm{SD})$ & $5.65 \pm 2.08$ & $6.28 \pm 4.94$ & $5.71 \pm 1.39$ \\
\hline $\mathrm{HDL}(\mathrm{mmol} / \mathrm{L})($ mean $\pm \mathrm{SD})$ & $1.22 \pm 0.44$ & $1.22 \pm 0.32$ & $1.27 \pm 0.50$ \\
\hline TGs $(m m o l / L)($ mean $\pm S D)$ & $1.50 \pm 0.99$ & $1.60 \pm 1.06$ & $1.60 \pm 1.44$ \\
\hline Waist $(\mathrm{cm})($ mean $\pm \mathrm{SD})$ & $90.94 \pm|3.9|$ & $97.24 \pm 14.09 * \ddagger$ & $87.25 \pm 14.73$ \\
\hline Weight $(\mathrm{kg})($ mean $\pm \mathrm{SD})$ & $74.81 \pm 14.48 \ddagger$ & $81.22 \pm 18.91 * \neq$ & $68.16 \pm 15.33$ \\
\hline MetS (IDF) n (\%) & $36(28.6 \%)$ & $40(35.7 \%)$ & $22(21.8 \%)$ \\
\hline
\end{tabular}

Notes: *Higher than the control group; ${ }^{\dagger}$ higher than the MD+AP group; thigher than the MD/noAP group $(p<00.05)$.

Abbreviations: HC, healthy controls; MD, mental disorder; AP, antipsychotics; SD, standard deviation; BMI, body mass index; SBP, systolic blood pressure; DSP, diastolic blood pressure; FBG, fasting blood glucose; HDL, high density lipoproteins; TG, triglycerides; MetS, metabolic syndrome; IDF, international diabetes federation.

noAP had a history of mental illness for over a year but stopped medications for six months or more. Both the duration of illness and the number of hospitalizations were longer in the MD/AP group (Table 2). The number of patients with a history of suicidal attempts was not significantly different between the two groups of patients. Few patients were receiving oral hypoglycemics or antihypertensives in the $\mathrm{HC}$ and $\mathrm{MD}$ /noAP groups, and thus comparisons were not warranted. In the MD+AP group, few patients were receiving selective serotonin reuptake inhibitors or valproate. The majority in this group was on SGA (mainly olanzapine and risperidone) (Table 2). The types of AP prescribed were: FGA only $(n=15,13.40 \%)$, SGA only $(n=72,64.29 \%)$, two SGA $(n=5,4.45 \%)$ and a combination of FGA and SGA $(n=20,17.86 \%)$. Psychiatric measures like the duration of illness, the number of admissions, and history of suicide were not significantly different in the two patient groups. 
Table 2 Psychiatric and medication profiles of patients' groups

\begin{tabular}{|c|c|c|}
\hline & $M D+A P(n=1 \mid 2)$ & MD/noAP $(n=|0|)$ \\
\hline \multicolumn{3}{|l|}{ Psychiatric diagnosis, n (\%) } \\
\hline Schizophrenia spectrum & $46(41.07 \%)$ & $49(48.51 \%)$ \\
\hline Psychosis NOS & $3(2.68 \%)$ & $12(11.88 \%)$ \\
\hline Depression & $8(7.14 \%)$ & $9(8.91 \%)$ \\
\hline Bipolar & $45(40.18 \%) \ddagger$ & $19(18.81 \%)$ \\
\hline Mood NOS & $3(2.68 \%)$ & 7 (6.93\%) \\
\hline OCD & $3(2.68 \%)$ & $2(1.98 \%)$ \\
\hline Personality & $4(3.57 \%)$ & $3(2.97 \%)$ \\
\hline Duration of illness (years) (Median \pm IQR) & $10 \pm 11.50 \ddagger$ & $3 \pm 5$ \\
\hline Number of psychiatric hospitalizations (Median \pm IQR) & $3 \pm 3 \ddagger$ & $1 \pm 1$ \\
\hline History of suicide attempts, n (\%) & $26(23.21 \%)$ & $18(17.82 \%)$ \\
\hline Oral hypoglycemics $(n)$ & 8 & 2 \\
\hline Antihypertensives (n) & 3 & 2 \\
\hline Antidepressants (n) & 12 & 4 \\
\hline Sodium valproate $(n)$ & 9 & - \\
\hline \multicolumn{3}{|l|}{ SGA (n) (CBZ equivalent AP dose) (Median \pm IQR) } \\
\hline Aripiprazole & $17(364.25 \pm 0.00)$ & - \\
\hline Paliperidone & $6(40|.33 \pm 5| 7.24)$ & - \\
\hline Risperidone & $36(253.05 \pm|72.4|)$ & - \\
\hline Olanzapine & $43(240.68 \pm 150.60)$ & - \\
\hline Quetiapine & $12(67.15 \pm 282.19)$ & - \\
\hline Clozapine & $4(80.08 \pm 109.25)$ & - \\
\hline \multicolumn{3}{|l|}{ FGA (n) (CBZ equivalent AP dose) (Median \pm IQR) } \\
\hline Haloperidol & $15(249.38 \pm 217.39)$ & - \\
\hline Flupenthixol* & 3 & - \\
\hline Zuclopenthixol* & 2 & - \\
\hline
\end{tabular}

Notes: *These AP were given as depot injection; fhigher than the MD/noAP group $(p<0.05)$.

Abbreviations: NOS, not otherwise specified; OCD, obsessive compulsive disorder; IQR, interquartile range; FGA, first generation antipsychotics; SGA, second generation antipsychotics; AP, antipsychotics.

\section{Sleep patterns by illness and treatment groups (Table 3 )}

The responses to the sleep questionnaire (SM1) are presented by subject groups in Table 3 . The factors related to the duration of sleep $\left(\mathrm{F}_{2,336}=22.134, p<0.001\right)$, early insomnia $\left(\chi^{2}=7.802, \quad p=0.020\right)$, and associated sleep problems $\left(\chi^{2}=9.884, p=0.007\right)$ showed significant differences across the three groups. Post hoc analysis showed that the mean duration of sleep was significantly higher in the two patient groups compared to HC. The number of patients sleeping $>8 \mathrm{~h}$ was also significantly higher in the two patient groups, while more subjects in HC slept 7-8 h (Table 3). The number of patients with early insomnia was significantly higher in $\mathrm{MD} /$ noAP compared to HC. More patients maintained on AP had sleeping problems compared to HC. There were no significant differences in the subject's rating of SQY, late insomnia or feeling sleepy during the day (Table 3). The sleep score calculated as per SM2 was higher in the two patient groups (on and off $\mathrm{AP}$ ) than the HC group. ANOVA test $\left(\mathrm{F}_{2,319}=3.211, p=0.042\right)$ was marginally significant but the Bonferroni-corrected post hoc comparisons did not reach statistical significance (Table 3).

\section{Sample characteristics by sleep duration groups (Table 4)}

In order to analyze the associations between the psychiatric and metabolic measures with SDN, we compared the sample variables among the three SDN groups. Our results showed that nationality $\left(\chi^{2}=24.273, p<0.001\right)$ and employment status $\left(\chi^{2}=29.157, p<0.001\right)$ were significantly different (Table 4$)$. Post hoc comparisons showed that the number of Qataris in the group sleeping $>8 \mathrm{~h}$ was higher than those in the other two groups. There were also significantly more unemployed people in the $>8 \mathrm{~h}$ group when compared to the other two groups 
Table 3 Sleeping patterns by illness and treatment groups

\begin{tabular}{|c|c|c|c|}
\hline & $H C(n=126)$ & $M D+A P(n=\mid 12)$ & MD/noAP $(n=|0|)$ \\
\hline Total number of hours slept (mean $\pm S D$ ) & $7.56 \pm 1.47$ & $9.17 \pm 2.08^{*}$ & $8.63 \pm 2.15^{*}$ \\
\hline \multicolumn{4}{|l|}{ Groups of hours slept, n (\%) } \\
\hline $7-8 \mathrm{~h}$ & $68(54.0 \%)^{\dagger} \ddagger$ & 35 (3I.8\%) & $34(33.7 \%)$ \\
\hline$<7 \mathrm{~h}$ & $30(23.8 \%)^{\dagger}$ & $8(7.3 \%)$ & $16(15.8 \%)$ \\
\hline$>8 \mathrm{~h}$ & $28(22.2 \%)$ & $67(60.9 \%) *$ & $51(50.5 \%) *$ \\
\hline Difficulty falling asleep, $\mathrm{n}(\%)$ & $20(16.0 \%)$ & 31 (28.2\%) & $31(30.7 \%)^{*}$ \\
\hline Early wakeup,n (\%) & $31(24.8 \%)$ & $34(30.9 \%)$ & $27(27.3 \%)$ \\
\hline Difficulty falling back into sleep $n(\%)$ & $21(16.7 \%)$ & $23(21.1 \%)$ & $26(26.3 \%)$ \\
\hline Tiredness/sleepiness, n (\%) & $37(29.6 \%)$ & $38(34.9 \%)$ & $37(36.6 \%)$ \\
\hline Problems during sleep, n (\%) & $26(21.3 \%)$ & $42(38.5 \%)^{*} \ddagger$ & $23(23.2 \%)$ \\
\hline \multicolumn{4}{|l|}{ Participants' rating of sleep quality, n (\%) } \\
\hline 1 & $4(3.2 \%)$ & $5(4.5 \%)$ & $4(4.0 \%)$ \\
\hline 2 & $6(4.8 \%)$ & $8(7.3 \%)$ & $8(8.1 \%)$ \\
\hline 3 & $27(2 \mathrm{I} .4 \%)$ & $27(24.5 \%)$ & $28(28.3 \%)$ \\
\hline 4 & $46(36.5 \%)$ & 35 (31.8\%) & $23(23.2 \%)$ \\
\hline 5 & $43(34.1 \%)$ & $35(31.8 \%)$ & $36(36.4 \%)$ \\
\hline Sleep score $($ mean $\pm S D)$ & $2.70 \pm 2.20$ & $3.4 I \pm 2.07$ & $3.29 \pm 2.53$ \\
\hline
\end{tabular}

Notes: *Higher than the control group; 'higher than the MD+AP group; thigher than the MD/noAP group $(p<0.05)$.

Abbreviations: HC, healthy controls; MD, mental disorder; AP, antipsychotics; SD, standard deviation.

(Table 4). The marital status or level of education in these SDN groups was not significantly different. The analysis of the clinical and metabolic measures across the three sleep groups showed that the following factors were significant: BMI $\left(\mathrm{F}_{2,323}=4.393, p=0.013\right)$, waist circumference $\left(\mathrm{F}_{2,333}=6.48\right.$, $p=0.002)$, weight $\left(\mathrm{F}_{2,329}=3.791, p=0.024\right)$, type of mental illness $\left(\chi^{2}=41.738, p<0.001\right)$, and type of $\mathrm{AP}\left(\chi^{2}=25.148\right.$, $p<0.001)$. Post hoc comparisons showed that the mean BMI, waist circumference, and weight were significantly higher in the $>8 \mathrm{~h}$ group compared to the other two groups. This group also had more subjects with psychotic or mood disorders compared to those sleeping 7-8 h or $<7 \mathrm{~h}$, which in turn had more HC subjects. Other variables like a history of medical problems, smoking status, BP, HDL, blood glucose and triglycerides levels were not significantly different in the three sleep groups. The number of subjects who met the criteria for MetS as per IDF was higher in the subjects sleeping $7-8 \mathrm{~h}$ or $>8 \mathrm{~h}$, but this increase did not reach statistical significance (Table 4).

\section{Multinomial logistic regression and sleep duration (Table 5)}

Using the variables that were significant (and clinically relevant) in the previous analyses, multinomial logistic regression was carried out to assess what factors are independent contributors to long or short SDN. The 7-8 h group was treated as the reference group against which short SDN ( $<7 \mathrm{~h}$ ) and long SDN ( $>8 \mathrm{~h})$ were compared. The predictors entered into the regression model were age, gender, nationality, subject group, smoking status, type of mental disorder, type of AP, BMI, weight, and waist circumference. The full regression model with all the predictors was significant $\left(\chi^{2}=58.057, \mathrm{df}=8, p<0.001\right)$. This was ascertained by the goodness-of-fit test $\left(\chi^{2}=624.471, \mathrm{df}=628, p=0.532\right)$. The predictors that remained significant after controlling for the other variables in the $>8 \mathrm{~h}$ group were gender, subject group and waist circumference (Table 5). For every $1 \mathrm{~cm}$ increase in waist circumference, there was a $1.9 \%$ increase in the odds of having longer SDN. Further, when compared to HC, patients in the MD+AP group had 4.282 times higher odds, and those in the MD/noAP group had 4.080 times higher odds of having longer SDN. As for gender, females were 2.119 times more prone to having longer SDN than males. No variables remained as significant predictors in the $<7 \mathrm{~h}$ group.

\section{Discussion}

Our study compared the self-reported SDN and SQY and the measured MetS risk factors in patients maintained on AP, patients not taking their psychotropics, and non-psychiatry 
Table 4 Sample characteristics by sleep duration groups

\begin{tabular}{|c|c|c|c|}
\hline & $7-8 h(n=137)$ & $<7 h(n=54)$ & $>8 h(n=146)$ \\
\hline Age (mean $\pm S D)$ & $36.37 \pm 9.29$ & $33.06 \pm 8.88$ & $34.52 \pm 8.96$ \\
\hline \multicolumn{4}{|l|}{ Gender, n (\%) } \\
\hline Male & $96(70.1 \%)$ & $36(66.7 \%)$ & $85(58.2 \%)$ \\
\hline Female & $4 \mathrm{l}(29.9 \%)$ & $18(33.3 \%)$ & $6 \mathrm{I}(4 \mathrm{I} .8 \%)$ \\
\hline \multicolumn{4}{|l|}{ Nationality, n (\%) } \\
\hline Qatari & $29(21.2 \%)$ & 7 (I3.0\%) & $56(38.4 \%)^{* \dagger}$ \\
\hline Arab (non-Qatari) & $34(24.8 \%)$ & $16(29.6 \%)$ & $31(21.2 \%)$ \\
\hline South Asian & $63(46.0 \%) \ddagger$ & $22(40.7 \%)$ & $39(26.7 \%)$ \\
\hline Other & II (8.0\%) & $9(16.7 \%)$ & $20(13.7 \%)$ \\
\hline \multicolumn{4}{|l|}{ Employment, n (\%) } \\
\hline Employed & $107(79.3 \%) \ddagger$ & $47(88.7 \%) \ddagger$ & 81 (55.5\%) \\
\hline Unemployed & $28(20.7 \%)$ & $6(11.3 \%)$ & $65(44.5 \%)^{* \dagger}$ \\
\hline Smoker, n (\%) Yes & 48 (35.0\%) & 17 (31.5\%) & 65 (44.5\%) \\
\hline BMI $\left(\mathrm{kg} / \mathrm{m}^{2}\right)($ mean $\pm \mathrm{SD})$ & $27.10 \pm 6.02$ & $25.17 \pm 4.43$ & $28.04 \pm 6.58^{\dagger}$ \\
\hline $\mathrm{SBP}(\mathrm{mm} \mathrm{Hg})($ mean $\pm \mathrm{SD})$ & $126.47 \pm 14.95$ & $123.41 \pm 15.69$ & $|25.77 \pm| 2.9 \mid$ \\
\hline $\mathrm{DBP}(\mathrm{mm} \mathrm{Hg})($ mean $\pm \mathrm{SD})$ & $80.03 \pm|2.6|$ & $76.09 \pm 12.10$ & $79.50 \pm 11.32$ \\
\hline $\mathrm{FBG}(\mathrm{mmol} / \mathrm{L})($ mean $\pm \mathrm{SD})$ & $5.88 \pm 2.23$ & $5.48 \pm 1.49$ & $6.02 \pm 4.30$ \\
\hline $\mathrm{HDL}(\mathrm{mmol} / \mathrm{L})($ mean $\pm \mathrm{SD})$ & $\mid .24 \pm 0.5 \mathrm{I}$ & $1.23 \pm 0.33$ & $1.23 \pm 0.37$ \\
\hline TGs $($ mmol/L) $($ mean $\pm \mathrm{SD})$ & $1.70 \pm 1.39$ & $1.31 \pm 0.81$ & $1.50 \pm 0.98$ \\
\hline Waist $(\mathrm{cm})($ mean $\pm \mathrm{SD})$ & $90.73 \pm 13.26$ & $86.34 \pm|2.4|$ & $94.43 \pm 16.11^{\dagger}$ \\
\hline Weight $(\mathrm{kg})($ mean $\pm \mathrm{SD})$ & $74.14 \pm 16.40$ & $69.98 \pm 12.43$ & $77.21 \pm 18.46^{\dagger}$ \\
\hline MetS (IDF), n (\%) Met & $43(31.4 \%)$ & $10(18.5 \%)$ & $44(30.1 \%)$ \\
\hline \multicolumn{4}{|l|}{ Type of MD, n (\%) } \\
\hline None & $68(49.6 \%) \ddagger$ & $30(55.6 \%) \ddagger$ & $28(19.2 \%)$ \\
\hline Psychotic disorders & $32(23.4 \%)$ & $15(27.8 \%)$ & $54(37.0 \%) *$ \\
\hline Mood disorders & $34(24.8 \%)$ & $8(14.8 \%)$ & $5 \mathrm{I}(34.9 \%)^{\dagger}$ \\
\hline Others & $3(2.2 \%)$ & I (I.9\%) & $13(8.9 \%)^{*}$ \\
\hline \multicolumn{4}{|l|}{ Type of Antipsychotics, n (\%) } \\
\hline None & $102(74.5 \%) \ddagger$ & $46(85.2 \%) \ddagger$ & 79 (54.1\%) \\
\hline First generation & $4(2.9 \%)$ & $3(5.6 \%)$ & $8(5.5 \%)$ \\
\hline Second generation & $26(19.0 \%)$ & $4(7.4 \%)$ & $46(31.5 \%)^{* \dagger}$ \\
\hline Both & $5(3.6 \%)$ & I (I.9\%) & $13(8.9 \%)$ \\
\hline
\end{tabular}

Note: *Higher than the 7-8 h; ${ }^{\dagger}$ higher than the $<7 \mathrm{~h}$ group; $\neq$ higher than the $>8 \mathrm{~h}$ group $(p<0.05)$.

Abbreviations: HC, healthy controls; MD, mental disorder; SD, standard deviation; BMI, body mass index; SBP, systolic blood pressure; DSP, diastolic blood pressure; FBG, fasting blood glucose; HDL, high density lipoproteins; TGs, triglycerides; MetS, metabolic syndrome; IDF, international diabetes federation.

controls. We also examined the relationship between SDN and the clinical and metabolic profiles of participants. The results will be discussed below according to these objectives.

Regarding the first objective, the group maintained on AP were mostly Qataris and smokers. Both groups of patients showed longer SDN and increased number of subjects sleeping $>8 \mathrm{~h}$ than $\mathrm{HC}$. More patients with insomnia were seen in the psychiatric group not taking AP, and higher frequency of associated sleep disorders was found in patients receiving AP (Table 1). Persistent early insomnia and interrupted sleep have been described before in both medicated and non-medicated schizophrenia patients. ${ }^{19}$ Previous studies that compared sleep patterns in patients with schizophrenia had shown that in nevermedicated or previously medicated patients, total SDN was reduced. ${ }^{6}$ These studies suggested that FGAs increase sleep efficiency while SGAs increase total sleep time. ${ }^{6}$ However, many of these studies did not have control 
Table 5 Factors associated with longer sleep duration using multinomial logistic regression

\begin{tabular}{|c|c|c|c|c|c|}
\hline & & \multirow[t]{2}{*}{ Odds ratio } & \multicolumn{2}{|c|}{ 95\% Confidence interval } & \multirow[t]{2}{*}{$p$-value } \\
\hline & & & Lower & Upper & \\
\hline \multirow[t]{4}{*}{$<7$ hrs } & Gender (Ref: Male) & 0.934 & 0.944 & $0.45 \mathrm{I}$ & 1.934 \\
\hline & Subject group: MD/noAP (Ref: HC) & 0.940 & 1.319 & 0.433 & 2.042 \\
\hline & Subject group: MD+AP (Ref: HC) & 0.508 & 1.230 & 0.199 & 1.296 \\
\hline & Waist circumference $(\mathrm{cm})$ & 0.978 & 1.004 & 0.953 & 1.004 \\
\hline \multirow[t]{4}{*}{$>8 \mathrm{hrs}$} & Gender (Ref: Male) & 2.119 & 1.222 & 3.674 & 0.008 \\
\hline & Subject group: MD/noAP (Ref: HC) & 4.080 & 2.111 & 7.887 & 0.000 \\
\hline & Subject group: MD+AP (Ref: HC) & 4.282 & 2.263 & 8.103 & 0.000 \\
\hline & Waist circumference $(\mathrm{cm})$ & 1.019 & $\mathrm{I} .00 \mathrm{I}$ & 1.038 & $0.04 I$ \\
\hline
\end{tabular}

Abbreviations: Ref, reference group; MD, mental disorder; AP, antipsychotics; HC, healthy controls.

groups and included only patients with schizophrenia. Studies on patients with mood disorders also showed more sleep problems, ${ }^{20}$ including difficulty remaining asleep, unsatisfactory SQY and abnormal SDN. SGAs, given to patients with unipolar ${ }^{21,22}$ or bipolar depression, ${ }^{23}$ and anxiety disorders, ${ }^{24}$ also demonstrated objective and subjective improvement in SQY. Our data also showed that the number of patients sleeping $<7 \mathrm{~h}$ and 7-8 $\mathrm{h}$ was significantly higher in $\mathrm{HC}$ and MD/noAP groups (Table 3 ). The sleep score was higher in the patient groups (on or off AP), but this increase did not reach significance (Table 2). Several studies confirmed our finding that sleep efficiency was reduced in patients with mental illness. ${ }^{6}$ When comparing scores on the Pittsburg Sleep Quality Index (PSQI), medicated schizophrenia patients showed a significant increase in these scores, signifying a poorer quality of sleep ${ }^{25}$ when compared to HC. We found only one study that assessed SQY in patients with various mental disorders and receiving adjunct AP. It concluded that sleep complaints persisted in patients receiving these AP, irrespective of the diagnosis. ${ }^{26}$ As such, evidence from previous studies supports our findings that the mental illness itself could be predisposing patients to poor sleep hygiene, and the effects of the AP are prolonging SDN but increasing the risk of having abnormal sleep patterns. It is worth adding that this is the first reported study concurrently comparing the sleep patterns in three groups: controls, medicated and non-medicated patients.

Regarding the second objective, our data showed that most of the patients sleeping regular hours $(7-8 \mathrm{~h})$ were from South Asia, employed, with no psychiatric illness and not taking AP. Most of the group sleeping $>8 \mathrm{~h}$ were Qataris, unemployed with mood or psychotic disorders, maintained on SGAs, and showed higher BMI, waist circumference, and weight compared to subjects sleeping $<7 \mathrm{~h}$ (Table 3). We did not find studies that assessed SDN with the metabolic profiles of patients with mental illness and on AP. However, our results are in concurrence with Arora's community study, which found that long SDN was linked to a higher risk of metabolic changes, and that chances of elevated triglycerides and central obesity were significantly higher in long sleepers. ${ }^{27}$ Brocato et al also established that SDN $>8 \mathrm{~h}$ was associated with cardiometabolic risk factors, namely hypertension, hyperglycemia, and obesity. ${ }^{28}$ On the other hand, chronic sleep loss was also shown to be a risk factor for the development of weight gain and DM type $2 .^{29}$ However, our results did not show higher blood glucose in the groups sleeping short or long hours $(<7 \mathrm{~h}$ or $>8 \mathrm{~h}$ ), maybe because our control population (which mostly slept 7-8 h) also had high blood glucose levels and comparable MetS prevalence to those sleeping $>8 \mathrm{~h}$. Further, the literature on the relationship between sleep and BMI is inconsistent. Some studies identified a negative correlation between SDN and BMI, where subjects with an increased BMI had shorter SDN; ${ }^{30,31}$ still, other studies found a U-shaped relationship between SDN and MetS. ${ }^{32}$ Many of the metabolic measures in our study were highest among patients maintained on AP, where the majority were sleeping $>8 \mathrm{~h}$. However, these metabolic changes were not significantly different from the control group, suggesting an increased number of metabolic abnormalities in the general population in Qatar and explaining the lack of significant differences in the prevalence of MetS among the three groups. The high frequency of obesity, DM, and high BP was demonstrated before in the general population of Qatar. ${ }^{14,33}$

The results of our regression analysis demonstrated that mentally ill patients had a higher likelihood of having more 
extended sleep hours than HC. The regression analysis of the factors independently and significantly associated with longer SDN were being female, having a psychiatric illness (on or off AP), and increased central obesity. Other studies also established that being a female was associated with longer SDN. ${ }^{34}$ For that matter, hormonal changes in women could likely be impacting their SDN and sleep patterns. ${ }^{35}$ Further, while research shows that insomnia is common in mentally ill patients, some studies established that specific categories of these patients (ex. bipolar depression patients) have increased SDN. ${ }^{5}$ Antipsychotic consumption might have also increased SDN in our patients, as those who were on AP were at a higher risk of hypersomnia than those who were not. Some studies implicated cytokines as the mediator for the effects of AP on sleep patterns. ${ }^{36}$ These changes in circadian rhythm were also linked to alterations in appetite hormones that could result in obesity, and the latter could further compromise sleep patterns. ${ }^{26,37}$ Other studies also revealed a positive association between longer SDN and waist circumference, specifically in women. ${ }^{38}$ Prospective consequences of a longer SDN include sleep fragmentation with poorer quality of sleep, daytime fatigue and a decreased ability to exercise, ${ }^{39}$ all of which contribute to a higher waist circumference.

\section{Limitations}

This study has few limitations that are worth mentioning as they can affect the generalizability of the results. First, most of the subjects in the patient groups were Qataris who were unemployed, as these are the most settled and most likely to seek treatment, whereas subjects in the control group were mostly working expatriates from South Asia. Thus, ethnicity, nationality, level of education, and work status could also have an impact on the duration of sleep in this study. Second, the heterogeneity of the sample that has multiple psychiatric diagnoses, different AP, intake of various psychotropics, and variable duration of illness and treatment, is a potential confounder to the generalizability of the findings to all mental disorders and all AP. Third, this is a cross-sectional study which limits inferential conclusions about causal relationships between sleep patterns, psychiatric illness, and metabolic abnormalities. Thus, more prospective studies that include specific mental disorders and controlled type of AP are needed to better understand these relationships. Fourth, the SDN used in our analyses was self-reported, and thus the reliability of these measures could be compromised, as actigraphy or polysomnographic recordings could have provided more accurate sleep measures. However, other studies have demonstrated similar results in psychiatric patients using objective and subjective sleep measures. ${ }^{39,40}$

\section{Conclusions}

Nonetheless, this is the first study to concurrently assess sleep and metabolic profile in medicated and non-medicated mentally ill patients and compare them to a control group. Our results showed that mental illness itself, regardless of treatment status, is associated with longer SDN, which is further aggravated by the use of AP. Besides, being a female and having central obesity are also significantly associated with longer SDN. Thus, psychiatrists should do more regular and detailed monitoring of sleep patterns in psychiatry patients, not only to improve the patients' mental health but also to prevent the development of metabolic changes.

\section{Data Availability Statement}

In order to protect the privacy and confidentiality of the research participants, our de-identified data is available only upon request and after compliance with the policies and procedures of WCM-Qatar, HMC and QNRF for data sharing. Requests can be submitted to Hassen Al-Amin at haa2019@qatar-med.cornell.edu.

\section{Acknowledgments}

We want to thank Dr. Azza Al-Mujalli for facilitating the recruitment of subjects from the primary care centers; and Dr. Marjonneke Mook-Kanamori for preparing the sleep questionnaire. This study was funded to Dr. $\mathrm{H} \mathrm{Al-Amin} \mathrm{as}$ a research grant from Qatar National Research Fund (QNRF) http://www.qnrf.org (NPRP 4-268-3-085). QNRF did not have any additional role in the study design, data collection and analysis, interpretation of data, decision to publish, or preparation of the manuscript.

\section{Author contributions}

N Kiwan contributed to data collection, statistical analysis, interpretation of results, and wrote the first draft of the manuscript. S Ghuloum contributed to study design and research conduct at the hospital. Z Mahfoud and A Yehya contributed to statistical analysis, data interpretation, and finalizing the results. Y Hani, R Chamali, and I Amro contributed to the preparation of research forms and data collection. D MookKanamori contributed to the preparation of research questionnaires. $\mathrm{H} \mathrm{Al}$-Amin is the principal investigator on this project, contributed to protocol and study design, data interpretation, manuscript writing, and supervised all study 
procedures. All authors contributed toward data analysis, drafting, and critically revising the paper, gave final approval of the version to be published, and agree to be accountable for all aspects of the work.

\section{Disclosure}

The authors report no conflicts of interest in this work.

\section{References}

1. Sokal J, Messias E, Dickerson FB, et al. Comorbidity of medical illnesses among adults with serious mental illness who are receiving community psychiatric services. J Nerv Ment Dis. 2004;192(6):421-427.

2. World Health Organization. Fact sheet. Premature death among people with severe mental disorders [Internet]. 2014. Available from: https://www.who.int/mental_health/management/info_sheet.pdf. Accessed July 15, 2019.

3. Robson D, Gray R. Serious mental illness and physical health problems: a discussion paper. Int J Nurs Stud. 2007;44(3):457-466. doi:10.1016/j.ijnurstu.2006.07.013

4. Cohrs S. Sleep disturbances in patients with schizophrenia: impact and effect of antipsychotics. CNS Drugs. 2008;22(11):939-962. doi:10.2165/00023210-200822110-00004

5. Krystal AD. Psychiatric disorders and sleep. Neurol Clin. 2012;30 (4):1389-1413. doi:10.1016/j.ncl.2012.08.018

6. Monti JM, Monti D. Sleep in schizophrenia patients and the effects of antipsychotic drugs. Sleep Med Rev. 2004;8(2):133-148. doi:10.1016/ S1087-0792(02)00158-2

7. Krystal AD, Goforth HW, Roth T. Effects of antipsychotic medications on sleep in schizophrenia. Int Clin Psychopharmacol. 2008;23 (3):150-160. doi:10.1097/YIC.0b013e3282f39703

8. Hung HC, Yang YC, Ou HY, Wu JS, Lu FH, Chang CJ. The relationship between impaired fasting glucose and self-reported sleep quality in a Chinese population. Clin Endocrinol (Oxf). 2013;78(4):518-524. doi:10.1111/j.1365-2265.2012.04423.x

9. Jennings JR, Muldoon MF, Hall M, Buysse DJ, Manuck SB. Selfreported sleep quality is associated with the metabolic syndrome. Sleep. 2007;30(2):219-223. doi:10.1093/sleep/30.2.219

10. Lakka HM, Laaksonen DE, Lakka TA, et al. The metabolic syndrome and total and cardiovascular disease mortality in middle-aged men. JAMA. 2002;288(21):2709-2716. doi:10.1001/jama.288.21.2709

11. Nagai M, Hoshide S, Kario K. Sleep duration as a risk factor for cardiovascular disease- a review of the recent literature. Curr Cardiol Rev. 2010;6(1):54-61. doi:10.2174/157340310790231635

12. Steptoe A, Peacey V, Wardle J. Sleep duration and health in young adults. Arch Intern Med. 2006;166(16):1689-1692. doi:10.1001/ archinte.166.16.1689

13. Choi KM, Lee JS, Park HS, Baik SH, Choi DS, Kim SM. Relationship between sleep duration and the metabolic syndrome: Korean National Health and Nutrition Survey 2001. Int J Obes (Lond). 2008;32(7):1091-1097. doi:10.1038/ijo.2008.62

14. Hammoudeh S, Ghuloum S, Mahfoud Z, et al. The prevalence of metabolic syndrome in patients receiving antipsychotics in Qatar: a cross sectional comparative study. BMC Psychiatry. 2018;18(1):81. doi:10.1186/s12888-018-1662-6

15. Sheehan DV, Lecrubier Y, Sheehan KH, et al. The Mini-International Neuropsychiatric Interview (M.I.N.I.): the development and validation of a structured diagnostic psychiatric interview for DSM-IV and ICD-10. J Clin Psychiatry. 1998;59 Suppl 20:22-33;quiz34-57.

16. Andreasen NC, Pressler M, Nopoulos P, Miller D, Ho BC. Antipsychotic dose equivalents and dose-years: a standardized method for comparing exposure to different drugs. Biol Psychiatry. 2010;67(3):255-262. doi:10.1016/j.biopsych.2009.08.040
17. Harzallah F, Alberti H, Ben Khalifa F. The metabolic syndrome in an Arab population: a first look at the new International Diabetes Federation criteria. Diabet Med. 2006;23(4):441-444. doi:10.1111/ j.1464-5491.2006.01866.x

18. Chaput JP, McNeil J, Despres JP, Bouchard C, Tremblay A. Seven to eight hours of sleep a night is associated with a lower prevalence of the metabolic syndrome and reduced overall cardiometabolic risk in adults. PLoS One. 2013;8(9):e72832. doi:10.1371/journal.pone.0072832

19. Monti JM, BaHammam AS, Pandi-Perumal SR, et al. Sleep and circadian rhythm dysregulation in schizophrenia. Prog Neuropsychopharmacol Biol Psychiatry. 2013;43:209-216. doi:10.1016/j.pnpbp.2012.12.021

20. Thase ME. Antidepressant treatment of the depressed patient with insomnia. J Clin Psychiatry. 1999;60 Suppl 17:28-31; discussion 46-28.

21. Lazowski LK, Townsend B, Hawken ER, Jokic R, Du Toit R, Milev R. Sleep architecture and cognitive changes in olanzapine-treated patients with depression: a double blind randomized placebo controlled trial. BMC Psychiatry. 2014;14:202. doi:10.1186/1471-244X14-202

22. Trivedi MH, Bandelow B, Demyttenaere K, et al. Evaluation of the effects of extended release quetiapine fumarate monotherapy on sleep disturbance in patients with major depressive disorder: a pooled analysis of four randomized acute studies. Int J Neuropsychopharmacol. 2013;16 (8):1733-1744. doi:10.1017/S146114571300028X

23. Kim SJ, Lee YJ, Lee YJ, Cho SJ. Effect of quetiapine XR on depressive symptoms and sleep quality compared with lithium in patients with bipolar depression. J Affect Disord. 2014;157:33-40. doi:10.1016/j.jad.2013.12.032

24. Mezhebovsky I, Magi K, She F, Datto C, Eriksson H. Double-blind, randomized study of extended release quetiapine fumarate (quetiapine XR) monotherapy in older patients with generalized anxiety disorder. Int $J$ Geriatr Psychiatry. 2013;28(6):615-625. doi:10.10 02/gps.3867

25. Afonso P, Figueira ML, Paiva T. Sleep-wake patterns in schizophrenia patients compared to healthy controls. World J Biol Psychiatry. 2014;15(7):517-524. doi:10.3109/15622975.2012.756987

26. Waters F, Faulkner D, Naik N, Rock D. Effects of polypharmacy on sleep in psychiatric inpatients. Schizophr Res. 2012;139(1-3):225228. doi:10.1016/j.schres.2012.05.013

27. Arora T, Jiang CQ, Thomas GN, et al. Self-reported long total sleep duration is associated with metabolic syndrome: the Guangzhou Biobank Cohort Study. Diabetes Care. 2011;34(10):2317-2319. doi:10.2337/dc11-0647

28. Brocato J, Wu F, Chen Y, et al. Association between sleeping hours and cardiometabolic risk factors for metabolic syndrome in a Saudi Arabian population. BMJ Open. 2015;5(11):e008590. doi:10.1136/ bmjopen-2015-008590

29. Spiegel K, Knutson K, Leproult R, Tasali E, Van Cauter E. Sleep loss: a novel risk factor for insulin resistance and Type 2 diabetes. $J$ Appl Physiol (1985). 2005;99(5):2008-2019. doi:10.1152/ japplphysiol.00660.2005

30. Vorona RD, Winn MP, Babineau TW, Eng BP, Feldman HR, Ware JC. Overweight and obese patients in a primary care population report less sleep than patients with a normal body mass index. Arch Intern Med. 2005;165(1):25-30. doi:10.1001/ archinte.165.1.25

31. Taheri S, Lin L, Austin D, Young T, Mignot E. Short sleep duration is associated with reduced leptin, elevated ghrelin, and increased body mass index. PLoS Med. 2004;1(3):e62. doi:10.1371/journal.pmed.001 0062

32. Mezick EJ, Matthews KA, Hall M, et al. Influence of race and socioeconomic status on sleep: Pittsburgh SleepSCORE project. Psychosom Med. 2008;70(4):410-416. doi:10.1097/PSY.0b013e31816fdf21

33. Al-Thani MH, Al-Thani AA, Cheema S, et al. Prevalence and determinants of metabolic syndrome in Qatar: results from a National Health Survey. BMJ Open. 2016;6(9):e009514. doi:10.1136/bmjopen-2015-009514 
34. Goel N, Kim H, Lao RP. Gender differences in polysomnographic sleep in young healthy sleepers. Chronobiol Int. 2005;22(5):905-915. doi:10.1080/07420520500263235

35. Shaver JL. Women and sleep. Nurs Clin North Am. 2002;37(4):707718.

36. Pollmacher T, Haack M, Schuld A, Kraus T, Hinze-Selch D. Effects of antipsychotic drugs on cytokine networks. J Psychiatr Res. 2000;34(6):369-382.

37. Ebdrup BH, Knop FK, Madsen A, et al. Glucometabolic hormones and cardiovascular risk markers in antipsychotic-treated patients. $J$ Clin Psychiatry. 2014;75(9):e899-e905. doi:10.4088/JCP.13m08820
38. Kim CE, Shin S, Lee HW, et al. Association between sleep duration and metabolic syndrome: a cross-sectional study. BMC Public Health. 2018;18(1):720. doi:10.1186/s12889-018-5557-8

39. Hamera E, Brown C, Goetz J. Objective and subjective sleep disturbances in individuals with psychiatric disabilities. Issues Ment Health Nurs. 2013;34(2):110-116. doi:10.3109/01612840.2012.729648

40. Hofstetter JR, Lysaker PH, Mayeda AR. Quality of sleep in patients with schizophrenia is associated with quality of life and coping. $B M C$ Psychiatry. 2005;5:13. doi:10.1186/1471-244X-5-13 


\section{Supplementary materials}

Table SI Sleep questionnaire

\begin{tabular}{|l|l|}
\hline \multicolumn{2}{|l|}{ Questions } \\
\hline 1 & How many hours do you, on average, sleep per day? \\
2 & Do you usually take naps during the day? \\
3 & Approximately how long is your nap? \\
4 & Do you often have difficulties falling asleep? \\
5 & Do you wake up earlier than you want? \\
6 & Do you often wake up after a short sleep and then have difficulty falling asleep again? \\
7 & Do you often feel tired/ sleepy during the day? \\
8 & Has anybody told you that you have any problems during sleep, like snoring, difficulty breathing, sleepwalking or others? \\
10 & What kind of problems during sleep do you have? \\
\hline
\end{tabular}


Table S2 Calculation of sleep score

\begin{tabular}{|c|c|c|c|}
\hline Component & Questions & Responses & $\begin{array}{l}\text { Sleep } \\
\text { scoring }\end{array}$ \\
\hline \multirow[t]{5}{*}{ I. Subjective sleep quality $(\mathrm{Cl})$} & \multirow{5}{*}{$\begin{array}{l}\text { 12. How would you rate the quality of your sleep over the last six } \\
\text { months? I= Poor, } 5=\text { Excellent }\end{array}$} & 1 & 4 \\
\hline & & 2 & 3 \\
\hline & & 3 & 2 \\
\hline & & 4 & 1 \\
\hline & & 5 & 0 \\
\hline \multirow[t]{2}{*}{ 2. Sleep latency $(\mathrm{C} 2)$} & \multirow[t]{2}{*}{ 6. Do you often have difficulties falling asleep? } & Yes & 1 \\
\hline & & No & 0 \\
\hline \multirow[t]{4}{*}{ 3. Sleep duration (C3) } & \multirow[t]{4}{*}{$\begin{array}{l}\text { I. How many hours do you on average sleep per day? } \\
\text { 5. Approximately how long is your nap? }\end{array}$} & $\begin{array}{l}\text { Add number of hours slept } \\
\text { at night and nap duration }\end{array}$ & \\
\hline & & $<7$ & 1 \\
\hline & & $7-8$ & 0 \\
\hline & & $>8$ & 1 \\
\hline \multirow[t]{8}{*}{ 4. Sleep disturbances (C4) } & \multirow{8}{*}{$\begin{array}{l}\text { 7, } 8 \text { \& } 10 \\
\text { 7. Do you wake up earlier than you want? } \\
\text { 8. Do you often wake up after a short sleep and then have a } \\
\text { difficulty falling asleep again? } \\
\text { 10. Has anybody told you that you have problems during sleep, like } \\
\text { snoring, difficulty breathing, sleepwalking or others? }\end{array}$} & Q7, Q8 \& Q10: & \\
\hline & & Yes & 1 \\
\hline & & No & 0 \\
\hline & & $\begin{array}{l}\text { Sum of Q7, Q8 \& Q10 } \\
\text { scores: }\end{array}$ & \\
\hline & & 0 & 0 \\
\hline & & 1 & 1 \\
\hline & & 2 & 2 \\
\hline & & 3 & 3 \\
\hline \multirow[t]{2}{*}{ 5. Daytime dysfunction (C5) } & \multirow[t]{2}{*}{ 9. Do you often feel tired/ sleepy during the day? } & Yes & 1 \\
\hline & & No & 0 \\
\hline
\end{tabular}

Neuropsychiatric Disease and Treatment

\section{Publish your work in this journal}

Neuropsychiatric Disease and Treatment is an international, peerreviewed journal of clinical therapeutics and pharmacology focusing on concise rapid reporting of clinical or pre-clinical studies on a range of neuropsychiatric and neurological disorders. This journal is indexed on PubMed Central, the 'PsycINFO' database and CAS, and is the official journal of The International Neuropsychiatric Association (INA). The manuscript management system is completely online and includes a very quick and fair peer-review system, which is all easy to use. Visit http://www.dovepress.com/testimonials.php to read real quotes from published authors. 